\title{
Biopolítica, guerra híbrida e reestruturação do capitalismo: a globalização como ela é
}

Biopolítica, guerra híbrida e reestruturação do capitalismo: a globalização como elaé

Biopolitique, guerre hybride et restructuration du capitalisme: la mondialisation telle qu'elle est

Biopolitics, hybrid war and restructuring of capitalism: globalization as it is. Biopolítica, guerra híbrida y reestructuración del capitalismo: la globalización tal como es

\section{Rafael Roxo}

\section{OpenEdition}

Journals

\section{Edição electrónica}

URL: http://journals.openedition.org/espacoeconomia/13376

DOI: 10.4000/espacoeconomia.13376

ISSN: 2317-7837

\section{Editora}

Núcleo de Pesquisa Espaço \& Economia

\section{Refêrencia eletrónica}

Rafael Roxo, « Biopolítica, guerra híbrida e reestruturação do capitalismo: a globalização como ela é », Espaço e Economia [Online], 18 | 2020, posto online no dia 21 abril 2020, consultado o 20 maio 2020. URL : http://journals.openedition.org/espacoeconomia/13376 ; DOI : https://doi.org/10.4000/ espacoeconomia.13376

Este documento foi criado de forma automática no dia 20 maio 2020.

(C) NUPEE 


\title{
Biopolítica, guerra híbrida e reestruturação do capitalismo: a globalização como ela é
}

\author{
Biopolítica, guerra híbrida e reestruturação do capitalismo: a globalização como \\ elaé \\ Biopolitique, guerre hybride et restructuration du capitalisme: la mondialisation \\ telle qu'elle est \\ Biopolitics, hybrid war and restructuring of capitalism: globalization as it is. \\ Biopolítica, guerra híbrida y reestructuración del capitalismo: la globalización \\ tal como es
}

Rafael Roxo

\section{Introdução}

1 Um aspecto a ser retomado em relação ao período contemporâneo é ideia da globalização como fábula, como sugere Milton Santos (2004), ou seja, como um processo que é em parte real, mas que oculta uma sorte de perversidades: a globalização como ela é. O crescimento sem precedentes do turismo global e sua concentração em algo de 80\% na Europa Ocidental e América do Norte, mostra não só as desigualdades entre o Norte e o Sul do planeta, mas também o crescimento da desigualdade social estimulada pelo neoliberalismo e pela acumulação flexível e financeirizada. A primeira grande epidemia de nosso tempo não só põe em xeque a crescente desigualdade entre países e regiões e entre ricos e pobres, como toda a fragilidade da circulação global de capitais, de pessoas e das mercadorias produzidas a partir do modelo just in time e produção em rede. Ademais, a pandemia e toda crise econômica e social derivadas indicam novas divisões geopolíticas, novas estratégias militares como as guerras híbridas, travadas no plano interno e externo dos países, novas biopolíticas que almejam o controle e a disciplina dos indivíduos e grupos. Mas as crises também se apresentam como 
possibilidade de refletirmos e colocarmos em prática uma nova globalização, como sugere Milton Santos (op cit), mais solidária e justa em termos socioespaciais.

2 No plano do vivido um cenário distópico, em parte real, em parte estimulado pela grande mídia e redes sociais, a necessidade dos lockouts e toda sorte de isolamento social afetaram toda a cadeia global de suprimentos, os comércios e serviços, a exemplo da brusca queda da indústria do turismo e empresas de transporte aéreo. $\mathrm{Na}$ América do Sul, em 10 de abril, os jornais noticiavam que a redução tráfego aéreo chegou a 80\%, no Brasil, a oferta dos voos foi reduzida em $90 \%$. Nas cidades, os escritórios e fábricas, shopping centers e centros comerciais e de serviços esvaziaram-se e as casas cheias de pessoas significam um novo cenário já previsto por autoridades sanitárias mundo afora. Nos principais habitats humanos, as cidades e espaços urbano-metropolitanos, as novas divisões se explicitaram. A divisão entre aqueles que podem se isolar em quarentena (o auto isolamento) - indivíduos com a possibilidade de trabalhar home office ou que contam com alguma segurança trabalhista -, e aqueles que não podem se isolar, pois dependem do trabalho informal e temporário ou de seus pequenos negócios. Mas, sobretudo, uma divisão entre possuidores de seguro saúde ou convênio médico, acesso a medicamentos e entre aqueles com acesso aos ausentes ou sobrecarregados sistemas de saúde públicos. Ou seja, diante da probabilidade que novas epidemias, a autocontenção ou reclusão temporária só será realmente segura e possível para os mais ricos que dispõem de condições para o distanciamento social e o isolamento.

Mike Davis (2020), discute, por exemplo, a disputa pelos medicamentos produzidos pela indústria farmacêutica. Ao considerarmos tal produção como algo realizado socialmente deveria estar disponível a toda população, indicando a necessidade de sua socialização. Harvey (2020), na mesma publicação, crê que a crise engendrada pela pandemia significa um aprofundamento da crise de 2008, e, na impossibilidade de criação de novas fronteiras de expansão do capital (papel atribuído à China na crise de 2008), na eventual ineficácia de socorro aos bancos e empresas, nas suas palavras "as únicas políticas que funcionarão, tanto econômica quanto politicamente, são muito mais socialistas do que qualquer coisa" (HARVEY, op cit, p.23).

Enfim, a globalização como a conhecemos, com base no modelo do estado neoliberal e no livre comércio, praticada pelas principais nações ocidentais e propagandeada e estimulada pela Organização Mundial de Comércio - OMC e pelo Fundo Monetário Internacional - FMI, evidenciou sua fragilidade diante da primeira grande epidemia mundial de nossos tempos. A própria ideia de mercado assume outras conotações que estavam ocultas até então. Conforme Pepe Escobar (2020a) as autoridades chinesas já previam uma nova epidemia como a ocorrida com SARS no início dos anos 2000. A epidemia de SARS, entre 2002 e 2003, teria se originado nos mercados de animais selvagens locais. O mercado de carnes exóticas e a produção destes animais em cativeiro, expandiu-se com a autorização do governo chinês durante os dois grandes períodos de fome do século XX. A atualmente o seu consumo é realizado sobretudo pela classe de novos empresários, classes médias e membros do partido comunista chinês. $O$ fechamento dos mercados de carnes selvagens já havia sido cogitado pelo governo de Pequim, no entanto a pressão dos mercadores e da indústria de animais impediram o seu fechamento. As gripes aviária, suína etc., a doença da vaca louca, as pragas agrícolas e a pandemia de Covid-19 evidenciam o risco à saúde humana, animal e do planeta produzido pelo mercado global de alimentos, por exemplo. 
5 O texto está dividido em três partes. Na primeira, analisamos a biopolítica contida na produção capitalista do espaço e as possibilidades da mesma durante a pandemia do coronavírus. Na segunda parte, analisamos as disputas geopolíticas acerca do destino do capitalismo e da globalização, com base na noção de guerra híbrida e os indícios da (nova) reestruturação capitalista. Nas considerações finais, buscamos apontar alguns cenários, a partir das argumentações expostas no presente artigo.

\section{A produção capitalista do espaço e sua dimensão biopolítica}

6 A relação entre a produção do espaço urbano e sua dimensão biopolítica remete a noção de metrópole biopolítica (NEGRI, 2014). o termo dimensiona a sociedade na sua relação com a reprodução do capital, como um processo de controle dos corpos e dos indivíduos para e pelo trabalho e a apropriação e o controle dos ritmos, fluxos e destino da produção e do consumo. Nesse sentido, o espaço produzido é compreendido como condição e produto da reprodução do capital, mas é o meio que possibilita a reapropriação das condições gerais de produção, aspectos todos estes evidenciados pelos enfrentamentos promovidos pelos movimentos sociais e nas disputas pelos bens comuns urbanos, por exemplo. A noção de bem comum urbano associa a produção e o espaço social como um direito à obra, de maneira semelhante a noção de direito à cidade ensejada por Henri Lefebvre. Avançando neste debate, Harvey (2014) mostra como os bens comuns se convertem no principal lugar de resistência e reivindicação: por meio de ocupações e apropriações do espaço público (comunalização), convertendo-o em um bem comum político, um lugar para o debate e a discussão aberta sobre as manobras do poder.

7 A biopolítica foi um tema explorado por autores como por Michel Foucault e Achille Mbembe. Michel Foucault (2010), retomando sua obra analisa como as instituições como a família, o quartel, a fábrica, a escola e o hospital exercem a função de tornar os corpos dóceis e disciplinados, a partir de não apenas da violência física, marca das antigas punições, mas sobretudo pela violência simbólica praticada pelo Estado e pelo modo de produção, em última instância controlando os desejos dos indivíduos. Achille Mbembe (2018), prolongando Foucault, descreve como num país colonizado, a soberania do colonizador revela-se como biopolítica de etnocídios e genocídios, mas enquanto países independentes o Estado passaria a gerenciar o direito de vida e de morte.

As relações biopolítica de controle dos corpos e dos movimentos são reconhecidas historicamente e permeiam a característica urbanística das cidades. No passado, a segregação centro-periferia das cidades dispunha da alocação dos matadouros, dos lazaretos, dos presídios, dos hospitais psiquiátricos, cemitérios, enfim nas áreas ocupadas pelos trabalhadores e mais pobres. Em tempos mais recentes, nas metrópoles e cidades médias o espaço urbano apresenta como característica a policentralidade e a fragmentação socioespacial, significando o surgimento de novas periferias e subcentralidades das cidades e da rede urbana. Processo todo esse que mascara uma maior apropriação dos espaços públicos pelo privado, não sem disputas como apontamos, ocultados por processos de espetacularização e simulação da realidade.

9 Nesse sentido, a cidade ou o espaço urbano-metropolitano é formado por um conjunto de objetos que se comunicam entre si, o sistema de transporte e o sistema de comunicação, mas também as formas de habitação e consumo são a expressão do 
macrossistema técnico e subssistemas, que possuem a capacidade (estética, arquitetônica, funcional) de fazer a simulação da realidade. Trata-se, na perspectiva de Baudrillard ([1981] 1991) da simulação da realidade em favor do sistema de trocas, no qual os automóveis, as estradas e os hiper-mercados e shopping centers associada à urbanização dispersa (sobretudo o modelo americano) são a maior expressão de uma hiper-realidade, que não só oculta a relações sociais de poder e controle, em meio às práticas socioespaciais fragmentadas, mas teríamos diante da mercadorização completa e a sociedade de consumo (como tendências) a desaparição do real.

o hipermercado é já, para além da fábrica e das instituições tradicionais do capital, o modelo de toda a forma futura de socialização controlada: retotalização no espaço-tempo homogêneo de todas as funções dispersas do corpo e da vida social (trabalho, tempos livres, alimentação, higiene, transportes, media, cultura) [..] espaço-tempo de toda uma simulação operacional da vida social, de toda uma estrutura de habitat e de tráfego. (BRAUDRILLARD, [1981] 1991, p.99)

10 Essas principais características da urbanização mundial (materiais e simbólicas) representam o principal meio de reprodução do capital - a produção do espaço -, mas como estamos propondo, a biopolítica praticada por meio do urbanismo contemporâneo, como estratégia de apartamento de grupos de classes sociais e etnias distintas. Como bem analisa Stephem Graham (2016), a partir da identificação da disseminação do urbanismo militar mundo afora, a partir do atentado ao WTC em 11 de setembro de 2001, a primeira grande guerra híbrida do século XXI, creio que a principal característica das disputas geopolíticas atuais, como veremos a seguir.

\section{A guerra híbrida e a reestruturação do capitalismo}

11 A guerra híbrida não é um aspecto novo, mas a estratégia da "guerra ao terrorismo" encabeçada por George W. Bush elevou-a a um novo patamar. Elementos da guerra não convencional já haviam sidos postos em prática, ao menos em parte, como estratégia de controle da Eurásia por Halford Mackinder e Nicholas Spykman, por exemplo. Conforme Andrew Korybko (2018), as guerras híbridas ou guerras não convencionais apresentam características distintas, pois são fluidas, descentralizadas e, principalmente, assimétricas. Voltadas, sobretudo, ao controle das reservas de recursos minerais e energéticos, principalmente no Oriente Médio, mas também na América Latina, e, disputas de mercados, com a Rússia, sobretudo. A guerra híbrida representa um conjunto de estratégias militares que mescla táticas de guerra convencional, guerra irregular e ciberguerra com outros métodos de guerra política, tais como diplomacia, lawfare e intervenção eleitoral externa, financiamento de atores políticos e redes de fake news. Korybko (2018) desvenda a participação dos EUA nas chamadas revoluções coloridas, como a Primavera Árabe e as manifestações no Leste Europeu, a derrubada do poder na Ucrânia. Como veremos a seguir, China e Rússia tiveram resposta à altura dispondo de alguns dos artefatos da guerra não convencional.

Trata-se, ao nosso ver, do aprofundamento da crise do sistema capitalista mundial, na qual as guerras híbridas emergem como forte componente para controlar o seu destino, e, nesse sentido, a crise do modelo neoliberal e a crise de 2008 já tinham pronunciado uma nova reestruturação do capitalismo. As disputas ideológicas, nos planos internos e externos dos países, e a manipulação de informação tornam-se elementos chaves para a manutenção do status quo. 
13 Um primeiro aspecto a se considerar nessa disputa é a crise da ideologia neoliberal, principalmente a disseminada crença de que iniciativa privada ou os "mercados" são eficazes e responsáveis em regular os aspectos da vida social como a saúde. Os sistemas de saúde nacionais, com base na iniciativa empresarial, mostraram-se no mínimo insuficientes. A estatização dos leitos privados na Espanha, o caos na Itália e nos EUA são expressões da ineficiência do modelo neoliberal de saúde. $O$ segundo aspecto que evidencia ineficácia do "mercado" é o conjunto de intervenções que vêm sendo feitas pelos países mundo afora. Por exemplo, nos Estados Unidos, o pacote de combate à pandemia e a crise econômica é de 2,2 trilhões de dólares. No Reino Unido, enquanto escrevemos esse texto o governo de Boris Johnson divulga que vai cobrir até $80 \%$ dos salários dos trabalhadores, pelo menos nos próximos três meses, e pagar até $80 \%$ dos rendimentos dos trabalhadores autônomos, dentre outras medidas. Na Alemanha houve o anúncio de um pacote de 750 bilhões de euros, o que corresponde a mais de $30 \%$ do seu PIB. É certo que muitas empresas e empresários têm se mostrado solidários e realizado doações para combater a pandemia. No entanto, é difícil avaliar o quanto que essas iniciativas são apenas marketing e publicidade, estratégia para obtenção de restituição de impostos ou caridade.

14 Terceiro, a oscilação do mercado financeiro e a crise econômica derivada do isolamento das populações mundo afora colocou em xeque as cadeias globais de suprimento e de mercado e novos contornos da disputa EUA e Rússia. Em relação a este tema, temos que destacar a guerra do petróleo travada entre a Rússia e Arábia Saudita, grande aliado dos EUA no Oriente Médio. Os russos interessados em abalar o mercado mundial, enxergaram na redução da demanda a possibilidade de atingir seu rival. Num recente encontro da OPEP+, conforme Escobar (2020b), a Rússia não aceitou a proposta da Arábia Saudita de reduzir a produção de petróleo para compensar a redução da demanda e manter os preços elevados. A Rússia insistiu em manter a produção elevada para derrubar os preços de petróleo e atingir o seu principal concorrente no mercado europeu. Desde o conflito com a Ucrânia, em 2012, a Rússia teve decretado uma série de embargos econômicos que dificultam o comércio do petróleo de seu país com a União Europeia. A partir desse embargo econômico, os Estados Unidos tomaram parte do mercado de petróleo da Rússia com a Europa. A opção de Moscou em manter a produção de petróleo elevada teve a finalidade de abalar o mercado financeiro e desestabilizar as empresas americanas que produzem petróleo de xisto, trabalham com subsídios estatais elevados e vem operando com déficit em caixa há anos. Como resultado da ação de Moscou o petróleo desabou de US\$ 70 para próximo de US\$30, uma das maiores desvalorizações da história, afetando de modo negativo as bolsas de valores pelo mundo.

Quarto, ainda no plano internacional, a disseminação do coronavírus aumentou as tensões entre Pequim e Washington, indicando um novo estágio na disputa entre potências, e, que ambos os países estão reagindo de forma distinta em relação a pandemia. Conforme Escobar (2020a), o porta-voz do ministério das relações exteriores da China expressou em um tweet, a possibilidade de que "poderia ser o exército dos Estados Unidos que levou epidemia para Wuhan". Esse fato significou que Pequim considera abertamente os Estados Unidos como uma ameaça a seu país, um degrau acima das disputas comerciais que envolvem ambos os países. O líder americano, Donald Trump, por sua, vez faz uso da epidemia para atacar Pequim, utilizando-se do termo "vírus chinês", busca manipular a opinião pública internacional e de seu país em 
relação aos verdadeiros efeitos da epidemia mundial. Trump acusa Pequim de se beneficiar das instabilidades do mercado para comprar empresas e ações nos EUA e mundo afora. $O$ certo é que grandes empresários e investidores do mercado financeiro estão se beneficiando da pandemia. As ações da Amazon, por exemplo, tiveram um grande crescimento após os fechamentos dos comércios tradicionais.

Também é fato que ambos os líderes mundiais se utilizam da retórica do bioterrorismo para defenderem seus interesses em relação aos desafios políticos nacionais e regionais. Xi Jinping, líder chinês, apareceu na linha de frente de combate ao vírus, mobilizou tropas, médicos, medicamentos, recursos financeiros etc. utilizando-se do discurso de "guerra do povo" e o combate aos "inimigos externos". Adotando o isolamento horizontal para conter o avanço da epidemia, contando inclusive com aumento da repressão policial, o monitoramento de informações e dados pessoais via internet e celulares, a mobilização de líderes locais etc., obteve relativo êxito. No entanto, podemos deduzir que as medidas de isolamento contribuíram para conter os protestos em Hong Kong, aumentar as restrições individuais no seu território e resguardar os poderes do governo central chinês. Em relação aos EUA, cremos na hipótese de que Donald Trump usa a desinformação para pôr em prática uma necropolítica que pode ter saído do controle. Sabemos que governantes deste calibre contam com o auxílio de suas agências de inteligência, que fornecem informações, cenários e projeções da epidemia, mas o referido líder político a negava até pouco tempo, alegando defender ou proteger a economia. Só a história permitirá comprovar ou negar tal hipótese.

\section{Considerações finais}

17 Neste texto analisamos as relações entre biopolítica, guerra híbrida e a reestruturação do capitalismo no contexto da pandemia do coronavírus. De modo algum tivemos a pretensão de exaurir o tema, pelo contrário, cremos que nossa contribuição seja propor uma leitura instrumental para os fenômenos em curso e indicar algumas tendências. Primeiro, o fim da globalização como a conhecemos, sobretudo com o aumento das tensões entre Estados Unidos, China e Rússia. As duas últimas potências alinhadas em termos geopolíticos, a incapacidade do EUA liderarem o combate mundial à pandemia $\mathrm{e}$ o fracasso interno indicam uma nova globalização mais centrada na China. A recusa do EUA de enviar recursos financeiros à Organização Mundial da Saúde - OMS, o Brexit, recentemente, e a guerra comercial entre China e EUA são algumas evidências do enfraquecimento das instituições supranacionais e de comércio mundial.

Segundo, dentro deste quadro, e, considerando o relativo sucesso no combate contra o coronavírus efetuado pela China, temos indícios de um mundo menos aberto, próspero e livre. Indicando o reforço dos Estados e dos nacionalismos e exacerbando o dilema entre democracias ou regimes autoritários. Nesse sentido, cremos que a noção de guerra híbrida possa instrumentalizar os novos aspectos que dirigem a realidade política dos países e regiões, seja em nome do dito mercado, com a continuidade da neoliberalismo como modelo político-econômico em crise, ou das sociedades, com a retomada dos ideais de bem-estar social. Esta última tendência dependerá de forças políticas de âmbito nacional e regional.

Terceiro, diante do aprofundamento da crise econômica, cremos na revisão, ao menos parcial, das cadeias globais de just in time, ou seja, haverá o estímulo às novas realocações e reestruturação das cadeias produtivas globais. Também haverá o 
crescimento de projetos e parcerias que estimulem a (re)industrilização de países e regiões centrais, sobretudo em ramos estratégicos como farmacêutico e médico hospitalar, além da comunicação como a internet 5G. Evidentemente que isso dependerá também dos conselhos executivos e de acionistas das empresas e dos recursos e ativos territoriais disponíveis às empresas e ramos produtivos.

Por fim, cremos, ainda que parcialmente, que essa pandemia possa servir a um propósito útil, pois em todos os países temos a expressão do poder do espírito humano e das coletividades, potencializado pelas redes de comunicação e internet, apesar dos simulacros que a ensejam. Diante da presente crise, temos novamente a possibilidade de crítica e revisão do paradigma vigente de produção, consumo e segregação socioespacial. Ou seja, com a pandemia e as medidas impostas, temos a possibilidade de enfrentamento efetivo (ideológico e prático) do mundo antigo e de construção de uma sociedade mais justa, em termos socioespaciais, ambientais e uma nova biopolitica, que seja de fato humana, pelo e para os seres humanos.

\section{BIBLIOGRAFIA}

BAUDRILLARD, Jean. Simulacros e simulação. Lisboa: Relógio d'Àgua, [1981]1991.

DAVIS, Mike, et al: Coronavírus e a luta de classes. Terra sem Amos: Brasil, 2020.

ESCOBAR, Pepe. China locked in hybrid war with US. Asia Times, 17/03/2020(a). Disponível em: https://asiatimes.com/2020/03/china-locked-in-hybrid-war-with-us/

. How black swans are shaping planet panic. Asia Times, 11/03/2020(b). Disponível em: https://asiatimes.com/2020/03/how-black-swans-are-shaping-planet-panic/

FOUCAULT, Michel. Microfísica do poder. Rio de Janeiro: Edições Graal, 2010.

GRAHAM, Stephen. Cidades Sitiadas. O novo urbanismo militar. São Paulo: Boitempo, 2016

HARVEY, David. As cidades rebeldes: do direito à cidade à revolução urbana. São Paulo: Martins Fontes, 2014.

KORYBKO, Andrew. Guerras híbridas, das revoluções coloridas aos golpes. São Paulo, Expressão Popular, 2018.

MBEMBE, Achille. Necropolítica. 3. ed., São Paulo: n-1 edições, 2018.

NEGRI, Antonio. Rem Koolhaas: Junkspace e metrópole biopolítica. Disponível em: Radical philosophy, tradução UniNômade BR,n.ำ154, 2014. Disponível em: <http://uninomade.net/tenda/ rem-koolhaas-junkspace-e-metropole-biopolitica/>

SANTOS, Milton. Por uma outra globalização: do pensamento único à consciência universal. 11. ed. Rio de Janeiro: Record, 2004. 


\section{RESUMOS}

O presente artigo busca analisar a atual crise do modo de produção capitalista e a aceleração de seu processo de reestruturação a partir da pandemia do coronavírus. A presente epidemia revela ideologias e práticas biopolíticas de controle e disciplinamento sociais, a partir da produção do espaço urbano, mas também, no plano nacional e internacional, as guerras híbridas, indicam disputas internas e externas pelo destino do capitalismo, da globalização e das sociedades.

Cet article cherche à analyser la crise actuelle du mode de production capitaliste et l'accélération de son processus de restructuration basé sur la pandémie de coronavirus. L'épidémie actuelle révèle des idéologies et des pratiques biopolitiques de contrôle social et de discipline, basées sur la production de l'espace urbain, mais aussi, aux niveaux national et international, des guerres hybrides, indiquent des conflits internes et externes sur le sort du capitalisme, de la mondialisation et des sociétés.

This article seeks to analyze the current crisis in the capitalist mode of production and the acceleration of its restructuring process based on the coronavirus pandemic. The current epidemic reveals ideologies and biopolitical practices of social control and disciplining, based on the production of urban space, but also, at the national and international levels, hybrid wars, indicate internal and external disputes over the fate of capitalism, globalization and societies.

Este artículo busca analizar la crisis actual en el modo de producción capitalista y la aceleración de su proceso de reestructuración basado en la pandemia de coronavirus. La epidemia actual revela ideologías y prácticas biopolíticas de control y disciplina social, basadas en la producción del espacio urbano, pero también, a nivel nacional e internacional, las guerras híbridas indican disputas internas y externas sobre el destino del capitalismo, la globalización y las sociedades.

\section{ÍNDICE}

Palabras claves: biopolítica, guerra híbrida, producción del espacio, reestructuración del capitalismo.

Mots-clés: biopolitique, guerre hybride, production d'espace, restructuration du capitalisme.

Keywords: biopolitics, hybrid war, production of space, restructuring of capitalism.

Palavras-chave: biopolítica, guerra híbrida, produção do espaço, reestruturação do capitalismo.

\section{AUTOR}

\section{RAFAEL ROXO}

Doutor em Geografia Humana pela Universidade de São Paulo - USP. E-mail:

rafaelroxo@hotmail.com 